\title{
Pituitary Adenylate Cyclase-Activating Polypeptide (PACAP), a Neuron-Derived Peptide Regulating Glial Glutamate Transport and Metabolism
}

\author{
Maciej Figiel and Jürgen Engele \\ Anatomie und Zellbiologie, Universität UIm, 89069 Ulm, Germany
}

In the brain, glutamatergic neurotransmission is terminated predominantly by the rapid uptake of synaptically released glutamate into astrocytes through the $\mathrm{Na}^{+}$-dependent glutamate transporters GLT-1 and GLAST and its subsequent conversion into glutamine by the enzyme glutamine synthetase (GS). To date, several factors have been identified that rapidly alter glial glutamate uptake by post-translational modification of glutamate transporters. The only condition known to affect the expression of glial glutamate transporters and GS is the coculturing of glia with neurons. We now demonstrate that neurons regulate glial glutamate turnover via pituitary adenylate cyclase-activating polypeptide (PACAP). In the cerebral cortex PACAP is synthesized by neurons and acts on the subpopulation of astroglia involved in glutamate turnover. Exposure of astroglia to PACAP increased the maximal velocity of $\left[{ }^{3} \mathrm{H}\right] \mathrm{glu}-$ tamate uptake by promoting the expression of GLT-1, GLAST, and GS. Moreover, the stimulatory effects of neuronconditioned medium on glial glutamate transporter expression were attenuated in the presence of PACAP-inactivating antibodies or the PACAP receptor antagonist PACAP 6-38. In contrast to PACAP, vasoactive intestinal peptide promoted glutamate transporter expression only at distinctly higher concentrations, suggesting that PACAP exerts its effects on glial glutamate turnover via PAC1 receptors. Although PAC1 receptordependent activation of protein kinase $A$ (PKA) was sufficient to promote the expression of GLAST, the activation of both PKA and protein kinase $C$ (PKC) was required to promote GLT-1 expression optimally. Given the existence of various PAC1 receptor isoforms that activate PKA and PKC to different levels, these findings point to a complex mechanism by which PACAP regulates glial glutamate transport and metabolism. Disturbances of these regulatory mechanisms could represent a major cause for glutamate-associated neurological and psychiatric disorders.

Key words: astrocytes; glutamate uptake; GLT-1; GLAST; glutamine synthetase; PKA; PKC
Glutamate is the major excitatory neurotransmitter in the mammalian CNS and is known to be involved in complex processes such as memory formation. Perturbation of glutamatergic neurotransmission is regarded as the major cause for several neurological and psychiatric disorders, including psychosis and epilepsy (Carlson and Carlson, 1990; Olney, 1990). Further, excess levels of extracellular glutamate are considered crucial for several neurodegenerative disorders such as amyotrophic lateral sclerosis (ALS), Alzheimer's disease, Huntington's disease, and Parkinson's disease (for review, see Whetsell and Shapira, 1993). A major step in glutamatergic neurotransmission is the rapid clearance of synaptically released glutamate from the extracellular space by sodium-dependent glutamate transport. Initially, a family of three high-affinity sodium-dependent glutamate transporters that differ in their kinetic properties was cloned from rodent brain: GLAST (Storck et al., 1992), GLT-1 (Pines et al., 1992), and EAAC-1 (Kanai and Hediger, 1992). Subsequently, homologous transporters have been identified in humans and termed EAAT-1, EAAT-2, and EAAT-3, respectively (Arizza et al., 1994). More recently, an additional transporter subtype,

Received Sept. 30, 1999; revised Feb. 2, 2000; accepted Feb. 22, 2000.

This work was supported by the state of Baden-Württemberg (Landesforschergruppe) and the Deutsche Forschungsgemeinschaft. We thank Drs. C. Pilgrim and $\mathrm{K}$. Schilling for critical comments on this manuscript.

Correspondence should be addressed to Dr. Jürgen Engele, Universität Ulm, Anatomie und Zellbiologie, 89069 Ulm, Germany. E-mail: juergen.engele@med izin.uni-ulm.de.

Copyright (C) 2000 Society for Neuroscience $\quad 0270-6474 / 00 / 203596-10 \$ 15.00 / 0$
EAAT-4, was identified in the human and rodent cerebellum (Fairman et al., 1995; Lin et al., 1998). Immunohistochemical as well as in situ hybridization studies of the rodent brain showed that EAAC-1 is localized exclusively to neurons and further revealed that GLAST and GLT-1 are expressed predominantly by glia (Rothstein et al., 1994; Lehre et al., 1995; Torp et al., 1997).

Astrocytes perform the majority of glutamate uptake in the brain (Rothstein et al., 1996). Moreover, astrocytes, but not neurons, are capable of metabolizing incorporated glutamate into glutamine by the enzyme glutamine synthetase (GS; for review, see Sonnewald et al., 1997). Downregulation of astrocytic glutamate transporter expression with antisense oligonucleotides leads to neurodegeneration and progressive paralysis (Rothstein et al., 1996). Despite the crucial role of astrocytes in the onset of glutamate-associated neurological diseases, our knowledge of extracellular signaling molecules regulating glial glutamate uptake and metabolism is rather limited. Several factors, including glutamate itself, biogenic amines, arachidonic acid, and amyloid $\beta$-peptide, were found to rapidly affect glutamate uptake by post-translational modification of glial glutamate transporters (for review, see Gegelashvili and Schousboe, 1998). To date, the only experimental condition found to affect the expression of glial glutamate transporters and GS is the coculturing of glia with neurons, an effect mimicked by the activation of $\mathrm{cAMP} /$ protein kinase A (PKA)-dependent signaling pathways in glial cells (Hayashi et al., 1988; Swanson et al., 1997; Schlag et al., 1998).

Pituitary adenylate cyclase-activating polypeptide (PACAP) is 
Table 1. RT-PCR primers and predicted product length

\begin{tabular}{|c|c|c|c|}
\hline mRNA & Primer sequence & Primer Length (bp) & Product length (bp) \\
\hline \multirow[t]{2}{*}{ PACAP } & 5'-AATGACCATGTGTAGCGGAGCA-3 & 22 & 485 \\
\hline & 5'-ТАTACСТTTTCCCTAGCACGGC-3' & 22 & \\
\hline \multirow[t]{2}{*}{ GLT-1 } & 5'-TTCCAGTCTCATCACAGGGCT-3' & 21 & 463 \\
\hline & 5'-GCCGAAAGCAATAAAGAATCC-3' & 21 & \\
\hline \multirow[t]{2}{*}{ GLAST } & 5'-TAAGTATCACAGCCACAGCCG-3' & 21 & 454 \\
\hline & 5'-GAGTAGGGAGGAAAGAGGAG-3' & 20 & \\
\hline \multirow[t]{2}{*}{ ACTIN } & 5'-CTACAATGAGCTGCGTGTGGC-3' & 21 & 271 \\
\hline & 5'-CAGGTCCAGACGCAGGATGGC-3' & 21 & \\
\hline
\end{tabular}

a member of the vasoactive intestinal peptide (VIP)/secretin/ glucagon family of peptides and represents the most potent activator of cAMP-dependent signaling pathways presently known. PACAP exists in two forms: PACAP-38, the predominant PACAP form in the nervous system, and PACAP-27, which comprises the $27 \mathrm{~N}$-terminal amino acids of PACAP-38 (for review, see Arimura, 1998). To date, three PACAP receptors have been described (for review, see Harmar et al., 1998). The PAC1 receptor, which exist in various splice variants (Spengler et al., 1993), is a PACAP-preferring receptor and binds VIP only with low affinity. VPAC1 and VPAC2 receptors show highaffinity binding for both PACAP and VIP. In the nervous system PACAP acts as a multifunctional peptide and is involved in such diverse processes as the regulation of hormonal secretion (for review, see Rawlings and Hezareh, 1996), energy metabolism (Magistretti et al., 1998), and neuronal survival (KienlenCampard et al., 1997; Villalba et al., 1997; Takei et al., 1998; Vaudry et al., 1998). In addition, PACAP is known to modulate glutamate signaling profoundly (Martin et al., 1995; Stella and Magistretti, 1996; Pellegri et al., 1998), probably by directly interfering with glutamate receptors of the NMDA type (Liu and Madsen, 1997).

In the present study we provide evidence that PACAP acts as a neuron-derived signal regulating the expression of the glial glutamate transporters GLT-1 and GLAST as well as of the glutamate-converting enzyme GS. Moreover, we demonstrate that PACAP differentially affects the expression of GLT-1 and GLAST via the PAC-1 receptor-dependent activation of protein kinase $\mathrm{C}(\mathrm{PKC})$ and/or PKA.

\section{MATERIALS AND METHODS}

Animals and collection of brain tissue. Brains were obtained from postnatal day (P)1 rat (Sprague Dawley; Charles River, Sulzfeld, Germany) or fos-lacZ transgenic mouse pups (generously provided by Dr. J. Morgan, St. Jude Children's Research Hospital, Memphis, TN). Cerebral hemispheres were dissected under sterile conditions and were collected in ice-cold PBS. In some experiments the cerebral hemispheres were obtained from embryonic day (E)17 rat embryos (crown-rump length, 19-21 $\mathrm{mm})$.

Cell cultures. Primary glial cultures were established from P1 rat or mouse cerebral hemispheres by following a recently established protocol (Franke et al., 1998). Dissected tissue pieces were incubated for $20 \mathrm{~min}$ in $\mathrm{Ca}^{2+}$ - and $\mathrm{Mg}^{2+}$-free Dulbecco's PBS (Life Technologies, Gaithersburg, MD) containing $0.1 \%$ trypsin and $0.02 \%$ EDTA. Trypsin action was terminated by transferring the tissue pieces to HBSS (Life Technologies) supplemented with $10 \%$ fetal calf serum. The tissue was dissociated gently by trituration through a plastic pipette. Cell suspension was centrifuged at $400 \times g$ for $5 \mathrm{~min}$, and the pellet was resuspended in MEM (Life Technologies) supplemented with 10\% horse serum (Life Technologies). Cells were plated onto $100 \mathrm{~mm}$ culture dishes (Costar, Cambridge, MA) coated with poly-D-ornithine $(0.1 \mathrm{mg} / \mathrm{ml}$; molecular weight, 30-70 kDa; Sigma, Deisenhofen, Germany). On reaching confluency the cultured cells were trypsinized and replated. After the third passage the cells were seeded into either 48-well cluster plates (uptake experiments, fos assay; Costar) or $100 \mathrm{~mm}$ culture dishes (immunoblot, RT-PCR analysis; Costar) and were maintained further with serum-free N2 medium additionally supplemented with PACAP-38 (from $10^{-7}$ to $10^{-11}$ $\mathrm{M}$; Calbiochem, Schwalbach, Germany), VIP (from $10^{-7}$ to $10^{-11} \mathrm{M}$; Calbiochem), dibutyryl cyclic AMP (dbcAMP; $10^{-4} \mathrm{M}$; Sigma), H89 (10 ${ }^{-5} \mathrm{M}$; Calbiochem), Gö6976 (10 ${ }^{-6} \mathrm{M}$; Calbiochem), fibroblast growth factor-2 (FGF-2; $25 \mathrm{ng} / \mathrm{ml}$; Life Technologies), or a combination of these factors as specified in the text. In some experiments the cultures were treated with neuron-conditioned medium in the presence of antiPACAP-38 antiserum (final dilution, 1:1000; Peninsula Laboratories, Heidelberg, Germany), the PACAP receptor antagonist PACAP-(6-38) (3 $\mu \mathrm{M}$; Bachem, Heidelberg, Germany), or anti-goat antiserum (final dilution, 1:1000; Vector Labs, Peterborough, UK).

Neuronal cultures were established from E17 cerebral hemispheres at 300,000 cells $/ \mathrm{cm}^{2}$ and were maintained with a modified serum-free N2 medium (Engele, 1998) for up to $4 \mathrm{~d}$.

$R T$-PCR analysis. Primers for PACAP, GLT-1, GLAST, and $\beta$-actin were designed with Oligo software. PACAP primers recognize a sequence in the PACAP precursor mRNA. The sequences of the primers and the sizes of the reaction products are given in Table 1. Total RNA was isolated from primary glial cultures by using the PeqGold isolation kit (Peqlab) according to the manufacturer's instructions. Total RNA concentration was measured by spectrophotometric absorbance at 260 $\mathrm{nm}$. A total of $20 \mu \mathrm{g}$ of RNA was reverse-transcribed by using $200 \mathrm{U}$ per $\mu \mathrm{l}$ of M-MLV (Promega, Madison, W I) and $2 \mu \mathrm{g}$ of random hexamer primers (Interactiva, Ulm, Germany). Obtained templates were amplified in a final volume of $50 \mu$ l. To increase the stringency of primer binding, we additionally supplemented the reaction mix with $2.5 \%$ DMSO. If not stated otherwise, amplification was performed with 30 PCR cycles of $50^{\circ} \mathrm{C}$ for $1 \mathrm{~min}$ in the presence of $20 \mathrm{pmol}$ of the respective primers. Reaction products were separated in an agarose gel and visualized with ethidium bromide. For quantitative analysis, target mRNA was coamplified with $\beta$-actin mRNA as an internal reference as described previously (Pesce et al., 1996). Reaction was performed with 20 pmol of primers for the target mRNA and 2 pmol of primers for the $\beta$-actin mRNA. The obtained reaction products were separated in a $1.5 \%$ agarose gel, and optical densities of the bands were determined by fluorescent image scanning. The ratio of optical densities was calculated and taken as a measure of the respective target mRNA.

Fos assay and immunocytochemistry. PACAP-responsive cells were identified in glial cultures of fos-lacZ transgenic mice as described previously (Engele and Schilling, 1996). Cultures were stimulated for $3 \mathrm{hr}$ with PACAP $\left(10^{-7} \mathrm{M}\right)$ and fixed with $2 \%$ paraformaldehyde for $30 \mathrm{~min}$. $\beta$-Galactosidase activity was visualized by incubating the cultures for 24 hr at $37^{\circ} \mathrm{C}$ with X-gal (1 mg/ml; Bachem).

For phenotypic characterization of $\beta$-galactosidase-positive cells, cultures were incubated for $24 \mathrm{hr}$ at $4^{\circ} \mathrm{C}$ with antibodies to either glial fibrillary acidic protein (GFAP; 1:1000; Accurate Chemicals, Westbury, NY) or GS (1:2000; Biogenesis, Sandown, NH). The immunoreaction was detected with the Vectastain ABC kit (Vector Labs) by using the appropriate biotinylated secondary antibodies (1:400; Vector Labs) and 3,3'-diaminobenzidine as a chromogen. Labeled cells were counted under microscopical observation at $200 \times$ within the diameter of a culture well, corresponding to a total area of $4 \mathrm{~mm}^{2}$. Analysis was performed on a total of 12 culture wells from two independent experiments.

Glutamate uptake. Glutamate uptake studies were performed in either 
sodium- or lithium-supplemented Tris buffer (Garlin et al., 1995) containing (in mM) 5 Tris base, $10 \mathrm{HEPES}, 140 \mathrm{NaCl}$ or LiCl, $2.5 \mathrm{KCl}, 1.2$ $\mathrm{CaCl}_{2}, 1.2 \mathrm{MgCl}_{2}, 1.2 \mathrm{~K}_{2} \mathrm{HPO}_{4}, 10$ dextrose, and the GS inhibitor methionine sulfoximine ( $1 \mathrm{~mm}$; Sigma). Radiolabeled glutamate $(1 \mu \mathrm{Ci}$ / ml; specific activity, $63 \mathrm{Ci} / \mathrm{mmol}$; Amersham, Braunschweig, Germany) and unlabeled glutamate were mixed to obtain a total glutamate concentration of $960 \mu \mathrm{M}$. The stock solution was diluted further with the respective uptake buffer to yield a glutamate concentration of 320,160 , 80 , and $40 \mu \mathrm{M}$ and added to third passage glial cultures $(250 \mu \mathrm{l} /$ well). Uptake was terminated by removing the radioactive solution and rinsing the cultures three times with ice-cold lithium-containing Tris buffer. Cells were lysed in $0.1 \mathrm{M} \mathrm{NaOH}$, and the amount of incorporated glutamate was determined by liquid scintillation counting of the cell lysate. Sodium-dependent glutamate uptake was defined to be the difference of the amount of radioactivity incorporated by glia in the presence of sodium- and lithium-containing buffer and was referred to the amount of protein determined in sister cultures (see below).

Cell lysates and membrane fractions. For immunoblot analysis the cultured glia were lysed by ultrasonification in $60 \mathrm{~mm}$ Tris- $\mathrm{HCl}$ containing $2 \%$ SDS and $10 \%$ sucrose. For treatment of glia with neuronal membranes the membrane fractions were prepared from cultured E17 neurons on day 4 of cultivation. Cells were lysed in $0.25 \mathrm{M}$ sucrose buffer at $4^{\circ} \mathrm{C}$, and the lysate was centrifuged at $1000 \times g$ for $10 \mathrm{~min}$. The supernatant was collected, and membranes were pelleted at $100,000 \times g$ for $1 \mathrm{hr}$ at $4^{\circ} \mathrm{C}$. The pellet was resuspended in N2 medium to obtain a final protein concentration of $1 \mathrm{mg} / \mathrm{ml}$. Protein contents of both cell lysates and membrane fractions were determined with the BCA protein estimation kit (Pierce, Rockford, IL).

Neuron-conditioned medium. To obtain neuron-conditioned medium (CM), we incubated high-density cultures of the E17 cortex $(300,000$ cells $/ \mathrm{cm}^{2}$ ) with serum-free $\mathrm{N} 2$ medium on day 2 of cultivation. After 48 $\mathrm{hr}$ the medium was collected and centrif uged at $3000 \times g$ to remove cells and membrane fragments. The $\mathrm{CM}$ was aliquoted and stored at $-70^{\circ} \mathrm{C}$.

Western blot analysis. Cell lysates were diluted 1:1 in sample buffer $(250$ $\mathrm{mm}$ Tris-HCl, $\mathrm{pH}$ 6.8, containing 4\% SDS, $10 \%$ glycerol, and $2 \%$ $\beta$-mercaptoethanol) and denatured at $95^{\circ} \mathrm{C}$ for $5 \mathrm{~min}$. Proteins $(5 \mu \mathrm{g} /$ lane) were separated by SDS-10\% PAGE and transferred to nitrocellulose by electroblotting. Nonspecific binding sites were blocked with 5\% nonfat milk for $30 \mathrm{~min}$, and then the blots were incubated overnight at $4^{\circ} \mathrm{C}$ with one of the following antibodies: anti-GLT-1 (1:4000; Chemicon, Temecula, CA), anti-GLAST (1:1000; Chemicon), or anti-GS (1:2000). The immunoreaction was detected with the enhanced chemiluminescence kit (Amersham). In all experiments, protein loading was controlled by staining the blots with actin antibodies (1:1000; Santa Cruz Biotechnologies, Santa Cruz, CA).

\section{RESULTS}

\section{Neurons are the major source for PACAP in the neocortex}

The synthesis of PACAP by CNS neurons has been demonstrated repeatedly (for example, see Koves et al., 1991; Kivipelto et al., 1992; Mikkelsen et al., 1994; Nielsen et al., 1998; Waschek et al., 1998). Whether PACAP also is provided by CNS glia is presently unknown. To address this issue, we initiated dissociated cell cultures from the E17 rat cortex, where 95\% of the cells represent microtubule-associated protein-2 (MAP-2)-immunoreactive (IR) neurons (Engele, 1998). In addition, cultures were initiated from the P1 rat cortex; these cultures were passaged three times. We have demonstrated that such "third passage cultures" predominantly consist of various glial cell types and are virtually devoid of neurons (Franke et al., 1998). Approximately $90 \%$ of the cells represent type-1 astrocytes; a smaller number (1\%) represent type- 2 astrocytes; the remaining cells are glial precursors and oligodendrocytes. RT-PCR analysis resulted in the detection of PACAP mRNA in neuronal cultures, but not in glial cultures maintained with several different culture media (Fig. 1). These included serum-free N2 medium, MEM containing $10 \%$ horse serum, and N2 medium supplemented with FGF-2 $(25 \mathrm{ng} / \mathrm{ml})$. Whereas serum promotes glial proliferation, serum-free medium induces morphological differentiation of astrocytes. FGF-2 exerts

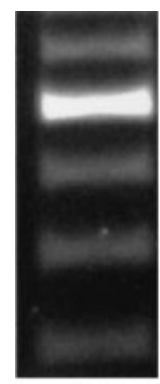

1

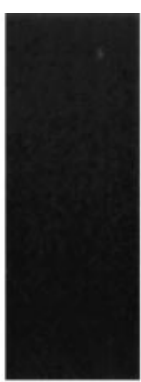

2

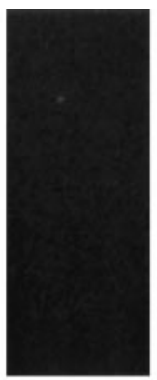

3

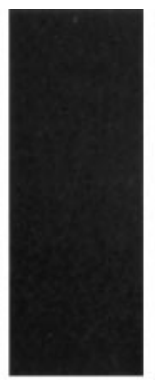

4

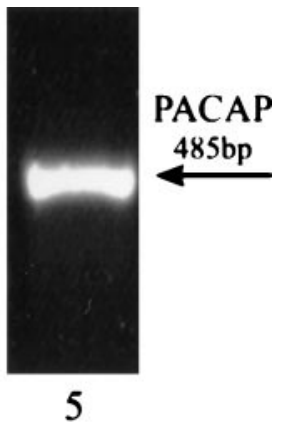

Figure 1. RT-PCR analysis allowed for the detection of mRNA encoding PACAP in 3-d-old cultures of E17 cortical neurons (lane 5). In contrast, PACAP signal was undetectable in the third passage glia of P1 rat cortical hemispheres maintained for $3 \mathrm{~d}$ with serum-free $\mathrm{N} 2$ medium (lane 2), N2 medium supplemented with FGF-2 (25 ng/ml; lane 3), or MEM supplemented with $10 \%$ horse serum (lane 4 ). Lane 1 shows a 100 bp ladder. In all cases the analysis was performed with 30 PCR cycles. The experiments were repeated three times with similar results.

a dual effect on glia: it is a potent mitogen for glial precursors and induces morphological differentiation of newly generated cells (Engele and Bohn, 1992). Because cultured glia developed in the virtual absence of neurons, we further considered the possibility that the presence of neurons is required to induce PACAP synthesis in glia. Glial cultures were maintained for $48 \mathrm{hr}$ either with CM derived from high-density $\left(300,000 \mathrm{cells} / \mathrm{cm}^{2}\right)$ cultures of E17 rat cortical neurons or with membrane fractions prepared from these neuronal cultures $(1 \mathrm{mg}$ of protein $/ \mathrm{ml})$. Both treatments failed to induce PACAP synthesis in cultured cortical glia (data not shown). Together, these findings suggest that neurons are the sole source for PACAP in the neocortex.

\section{PACAP acts on astroglia involved in glutamate turnover}

Although glial cells are an established target for PACAP in the CNS (Tatsuno and Arimura, 1994; Tatsuno et al., 1996; Magistretti et al., 1998; Moroo et al., 1998), both the number and the nature of PACAP-sensitive glia are presently not well defined. To characterize these targets, we have taken advantage of the fact that the initial genomic response of cells to a variety of extracellular stimuli consists in the rapid and transient expression of immediate early genes, most prominent among them $c$-fos (Schilling et al., 1991). PACAP-induced $c$-fos expression was monitored in cultures derived from a fos-lac $\mathrm{Z}$ transgenic mouse line (Smeyne et al., 1992). This experimental approach allows for the selective detection of $c$-fos expression (Schilling et al., 1991) and further favors the easy and rapid phenotypic characterization of $c$-fos-positive cells by the use of cell type-specific antibodies (Engele and Schilling, 1996). Third passage glial cultures were established from the cortex of P1 transgenic mouse pups, and confluent cultures were stimulated for $3 \mathrm{hr}$ with PACAP $\left(10^{-7} \mathrm{M}\right)$; this stimulation protocol leads to maximal transgene expression (Schilling et al., 1991; Engele and Schilling, 1996). Histochemical staining for $\beta$-galactosidase revealed that a major portion (96 \pm $2 \%$, mean $\pm \mathrm{SD} ; n=12$ culture wells) of the cultured cells showed transgene expression and thus responded to PACAP (Fig. $2 A$ ). A similar portion of cells responded to PACAP with $\beta$-galactosidase expression in subconfluent glial cultures (data not shown). This further demonstrates that $c$-fos expression results from the direct activation of the respective PACAP receptor(s) and does not involve an intermediate signal (Engele and Schilling, 

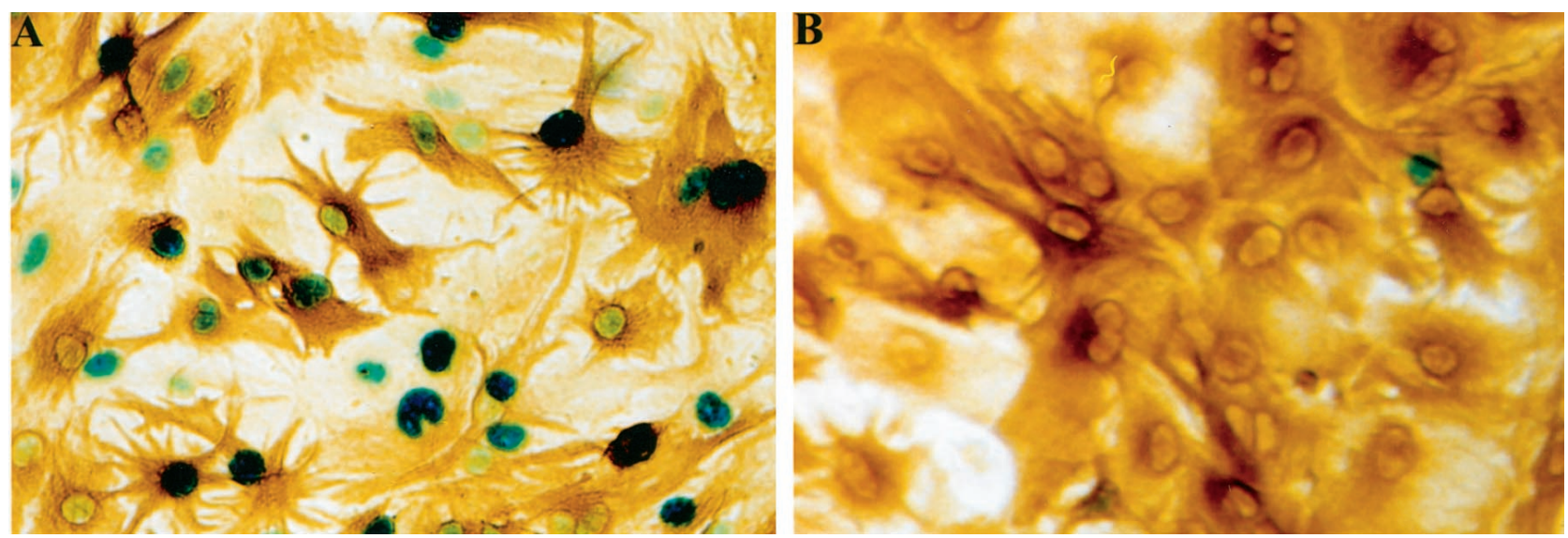

Figure 2. PACAP induces $c$-fos expression in astrocytes. A, Third passage glial cultures were initiated from the cerebral hemispheres of P1 fos-lac Z transgenic mice. Cultures were stimulated for $3 \mathrm{hr}$ with PACAP $\left(10^{-7} \mathrm{M}\right)$ and processed for $\beta$-galactosidase histochemistry and GFAP immunocytochemistry. $B$, Transgene expression in unstimulated control cultures. Magnification, $500 \times$. Note that the major portion of GFAP-IR astrocytes (brown) responds to PACAP with transgene expression (blue).

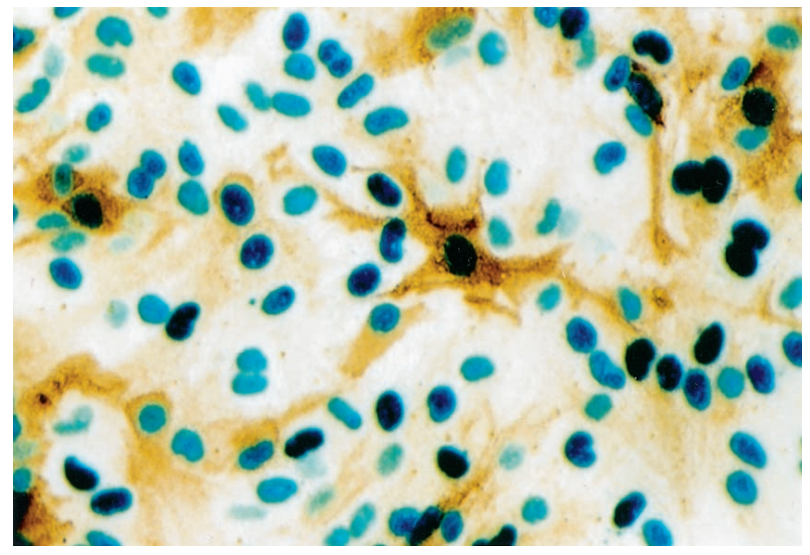

Figure 3. Double labeling of PACAP-stimulated $\left(10^{-7} \mathrm{M} ; 3 \mathrm{hr}\right)$ fos-lac $\mathrm{Z}$ transgenic mouse glia for $\beta$-galactosidase activity (blue) and GS immunoreactivity (brown) demonstrates that PACAP acts on astroglia involved in glutamate turnover. Magnification, $500 \times$.

1996). Independent of the culture conditions, $\beta$-galactosidase staining was basically absent from untreated controls (Fig. 2B). Subsequent double labeling of PACAP-stimulated cultures with antibodies against the astrocytic marker GFAP demonstrated that $92 \pm 3 \%(n=12)$ of the $\beta$-galactosidase-positive cells in culture were astrocytes (Fig. $2 A$ ). In the intact brain the expression of glutamate transporters is seen predominantly in those astrocytes located in the vicinity of glutamatergic nerve terminals (Rothstein et al., 1994; Lehre et al., 1995). This functional difference seems to persist in vitro because only a subpopulation of cultured astrocytes expresses the glial glutamate transporters GLT-1 and GLAST as well as the enzyme GS (Hallermayer and Hamprecht, 1984; Schlag et al., 1998). On the basis of these observations we sought to determine whether PACAP acts on astroglia involved in glutamate turnover. Third passage glial cultures were initiated from fos-lac Z transgenic mice and stimulated for $3 \mathrm{hr}$ with PACAP $\left(10^{-7} \mathrm{M}\right)$. Subsequent staining for $\beta$-galactosidase and GS revealed that $83 \pm 2 \%(n=12)$ of all GS-IR cells showed $\beta$-galactosidase activity (Fig. 3 ). Together, these findings demonstrate that PACAP acts on the major portion of CNS glia, including those involved in glutamate turnover.
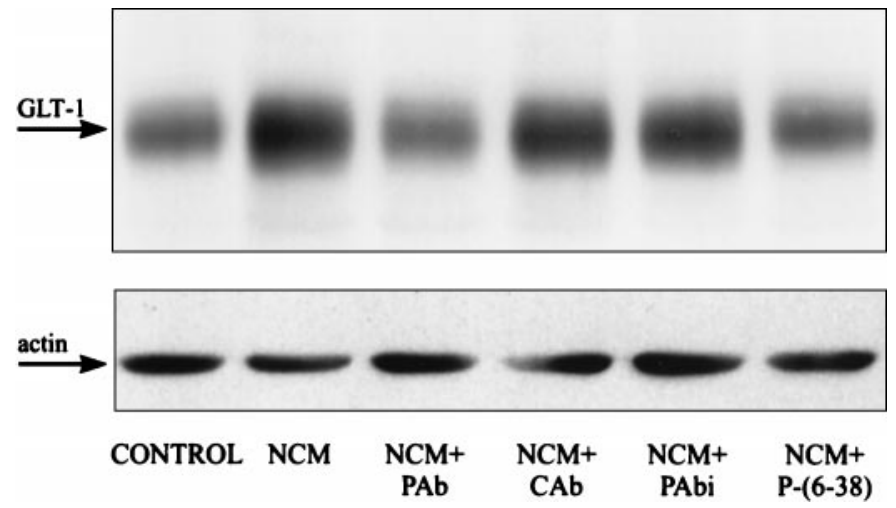

Figure 4. Influences of neuron-CM on glial glutamate transporter expression are mediated by PACAP. Neuron-CM $(N C M)$ was prepared from high-density cultures of E17 cortical neurons as described under Materials and Methods. Third passage glia were initiated from P1 rat cortical hemispheres and treated with either NCM alone or in combination with anti-PACAP-38 antibodies $(P A b)$, anti-goat control antiserum $(C A b)$, heat-inactivated PACAP-38 antibodies (PAbi), or PACAP-(6-38) [P-(6-38)]. After $3 \mathrm{~d}$ the GLT-1 expression levels were determined by immunoblot analysis. In each lane $5 \mu \mathrm{g}$ of total protein was loaded. Loading was controlled additionally by staining the blots with actin antiserum. The experiments were repeated three times with similar results.

\section{Neuronal influences on glial glutamate uptake are mediated by PACAP}

The demonstration of PACAP as a neuron-derived peptide that acts on the subpopulation of cortical glia involved in glutamate turnover prompted us to determine whether PACAP is the physiological mediator of the effects of neurons on glial glutamate transporter expression. Corroborating previous studies (Schlag et al., 1998), the treatment of rat glial cultures with neuron-CM for $2 \mathrm{~d}$ increased GLT-1 protein levels (Fig. 4). These stimulatory effects were abolished in the presence of PACAP-38 antiserum or the PACAP receptor antagonist PACAP-(6-38). Similar inhibitory effects were absent in the presence of equal concentrations of an unrelated (anti-goat) control antiserum or with heatinactivated $\left(45 \mathrm{~min}\right.$ at $100^{\circ} \mathrm{C}$ ) PACAP-38 antiserum (Fig. 4). Together, these findings demonstrate that PACAP regulates the expression of GLT-1, the glutamate transporter subtype previ- 
ously found to perform $>90 \%$ of total glutamate re-uptake in the brain (Tanaka et al., 1997). In contrast to GLT-1, neuron-CM promoted the expression neither of GLAST nor of GS. Presently, the most plausible explanation for this failure is that both GLAST and GS expression are affected by PACAP at a concentration distinctly higher than that present in the $\mathrm{CM}$ (see also Fig. 9).

\section{PACAP promotes glutamate uptake and metabolism in astroglia}

To analyze further the effects of PACAP on glial glutamate turnover, we maintained third passage glia of rat cortical hemispheres for $72 \mathrm{hr}$ with PACAP-38 $\left(10^{-7} \mathrm{M}\right)$ and subsequently tested them for sodium-dependent uptake of radiolabeled glutamate. All uptake studies were performed in the presence of the GS inhibitor methionine sulfoximine $(1 \mathrm{~mm})$; this approach allowed us to study PACAP effects on glutamate transport mechanism(s) independent of PACAP effects on intracellular enzymatic glutamate cleavage. PACAP effects were compared with those of dbcAMP, which previously was found to promote glial glutamate uptake (Swanson et al., 1997; Schlag et al., 1998). A representative uptake experiment is shown in Figure 5. For untreated astrocytes the average $V_{\max }$ value, as determined from three independent experiments, was $33 \pm 8 \mathrm{nmol} / \mathrm{min}$ per $\mathrm{mg}$ of protein; the average $K_{\mathrm{m}}$ value was $63 \pm 13 \mu \mathrm{M}$. PACAP resulted in an increase of the apparent $V_{\max }(52 \pm 7 \mathrm{nmol} / \mathrm{min}$ per $\mathrm{mg}$ of protein; $p=0.02$; unpaired Student's $t$ test) and $K_{\mathrm{m}}$ value (146 \pm $8 \mu \mathrm{M} ; p<0.001)$. Similar increases in the apparent $V_{\max }(46 \pm 2$ $\mathrm{nmol} / \mathrm{min}$ per $\mathrm{mg}$ of protein; $p=0.05)$ and $K_{\mathrm{m}}(123 \pm 20 \mu \mathrm{M} ; p=$ $0.005)$ of the uptake process were present in dbcAMP-treated cultures. With both PACAP and dbcAMP the effects on the uptake process were detectable only after prolonged treatment ( $\geq 2 \mathrm{~d}$ ). Currently, no specific inhibitors are available that would allow us to discern between GLT-1 and GLAST-mediated glutamate uptake. Although dihydrokainate has been shown to act as a specific inhibitor for GLT-1 expressed in a heterologous system (Pines et al., 1992; Arizza et al., 1994), it fails to affect GLTmediated glutamate uptake in primary glia (Schlag et al., 1998).

To determine whether PACAP increased astrocytic glutamate uptake by affecting GLAST and/or GLT-1, we studied expression levels of both transporters in cultured rat glia by immunoblot analysis, using GLT-1 and GLAST-specific antibodies (Fig. 6). In freshly prepared cell lysates the GLT-1 and GLAST antiserum each recognized a single protein with apparent molecular weights of 71 and $66 \mathrm{kDa}$, respectively. Freezing the samples before the analysis sometimes produced a second immunoreactive band of higher molecular weight. In accordance with previous reports (Swanson et al., 1997; Schlag et al., 1998), untreated third passage glia usually contained only low levels of GLAST and somewhat higher levels of GLT-1 (Fig. 6). Prolonged treatment (72 hr) of the cultures with PACAP-38 $\left(10^{-7} \mathrm{M}\right)$ resulted in robust increases of both GLT-1 and GLAST protein levels (Fig. 6). Densitometric analysis of the immunoblots from three independent experiments showed that this increase was $2.4 \pm 0.6$-fold for GLT-1 and $2.7 \pm$ 0.9 -fold for GLAST $(p \leq 0.01)$. In dbcAMP-treated cultures $\left(10^{-4} \mathrm{M} ; 72 \mathrm{hr}\right)$ the GLT- 1 and GLAST protein levels increased $3.7 \pm 0.9$-fold and $3.4 \pm 0.5$-fold, respectively $(p \leq 0.01)$. Because expression of glutamate transporters seems to be regulated at both the transcriptional and translational level (for review, see Gegelashvili and Schousboe, 1998), we further examined whether PACAP affects levels of glutamate transporter mRNAs. RT-PCR analysis demonstrated that a $72 \mathrm{hr}$ treatment with PACAP-38
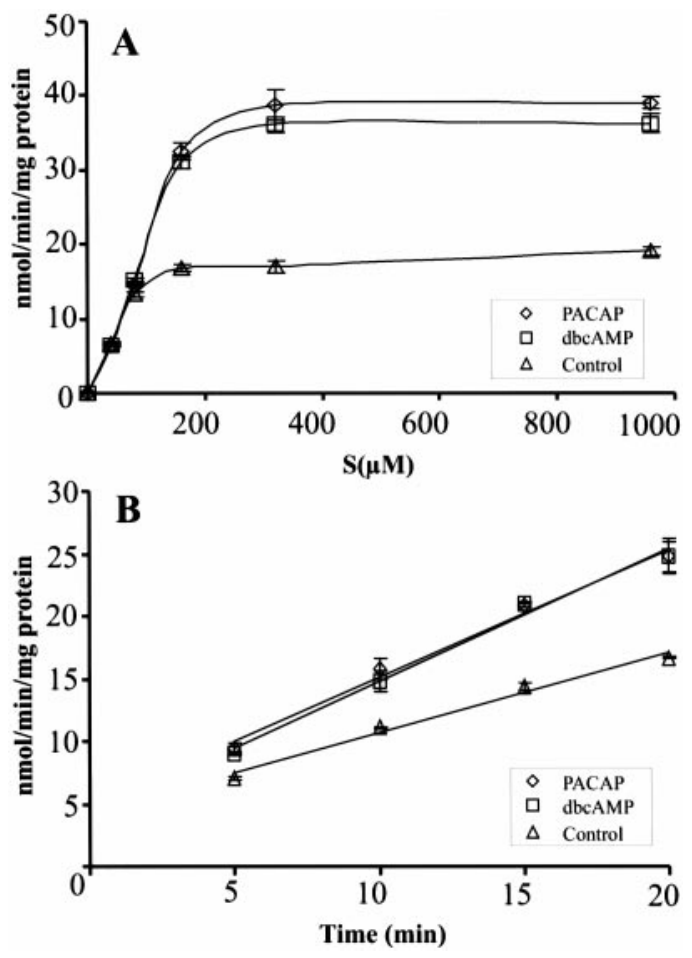

Figure 5. A, Effects of PACAP and dbcAMP on the kinetic parameters of glial glutamate uptake. Third passage cortical glia were maintained for $3 \mathrm{~d}$ in the absence or presence of PACAP $\left(10^{-7} \mathrm{M}\right)$ or $\operatorname{dbcAMP}\left(10^{-4} \mathrm{M}\right)$, and sodium-dependent glutamate uptake was determined by incubating the cultures with the indicated concentrations of tritiated glutamate, as described under Materials and Methods. Incubation was terminated after 10 min, a time point within the linear phase of glial glutamate uptake (see $B)$. Then the cells were lysed, and incorporated radioactivity was determined by liquid scintillation counting. Linear regression analysis of the data was performed with the Hanes transformation. Untreated control, apparent $V_{\max }=23 \mathrm{nmol} / \mathrm{min}$ per $\mathrm{mg}$ of protein; apparent $K_{\mathrm{m}}=57 \mu \mathrm{M}$; $r^{2}, 0.99$. With PACAP, apparent $\mathrm{V}_{\max }=47 \mathrm{nmol} / \mathrm{min}$ per $\mathrm{mg}$ of protein; apparent $K_{\mathrm{m}}=142 \mu \mathrm{M} ; r^{2}, 0.96$. With dbcAMP, apparent $\mathrm{V}_{\max }=48$ $\mathrm{nmol} / \mathrm{min}$ per $\mathrm{mg}$ of protein; apparent $K_{\mathrm{m}}=124 \mu \mathrm{M} ; r^{2}, 0.97$. Data represent the mean $\pm \mathrm{SD}(\mathrm{n}=12$ wells). $B$, Time course of sodiumdependent glutamate incorporation into glia, demonstrating that glial glutamate uptake is linear for at least $20 \mathrm{~min}$. Cultures were treated with PACAP and dbcAMP as described in $A$ and were incubated with a final glutamate concentration of $160 \mathrm{~mm}$. Data represent the mean $\pm \mathrm{SD}(n=$ 12 wells).

$\left(10^{-7} \mathrm{M}\right)$ stimulates the expression of mRNAs encoding GLT-1 and GLAST (Fig. 7). The average increase was $1.8 \pm 0.3$-fold and $1.3 \pm 0.1$-fold for GLT- 1 mRNA and GLAST mRNA, respectively $(n=3 ; p \leq 0.05)$. Similar increases were present in dbcAMP-treated cultures (GLT-1 mRNA, $2.1 \pm 0.5$-fold; GLAST mRNA, $1.6 \pm 0.2$-fold; $p \leq 0.05$ ).

In the next set of experiments we asked whether PACAP also affects the expression of the glutamate-converting enzyme GS. To follow up this possibility, we maintained third passage glial cultures of rat cerebral hemispheres for $72 \mathrm{hr}$ with PACAP-38 $\left(10^{-7}\right.$ M) or dbcAMP $\left(10^{-4} \mathrm{M}\right)$ and examined them for GS expression by immunoblot analysis. GS antibodies labeled a single protein band with an apparent molecular weight of $45 \mathrm{kDa}$. In both PACAP- and dbcAMP-treated cultures, GS protein levels clearly were increased as compared with untreated control (Fig. 8). For PACAP-treated cultures the average increase was $2.9 \pm 0.4$-fold, and for dbcAMP-treated cultures the increase was $5.1 \pm 1.5$-fold $(n=3 ; p \leq 0.01)$. This demonstrates that, in addition to affecting 

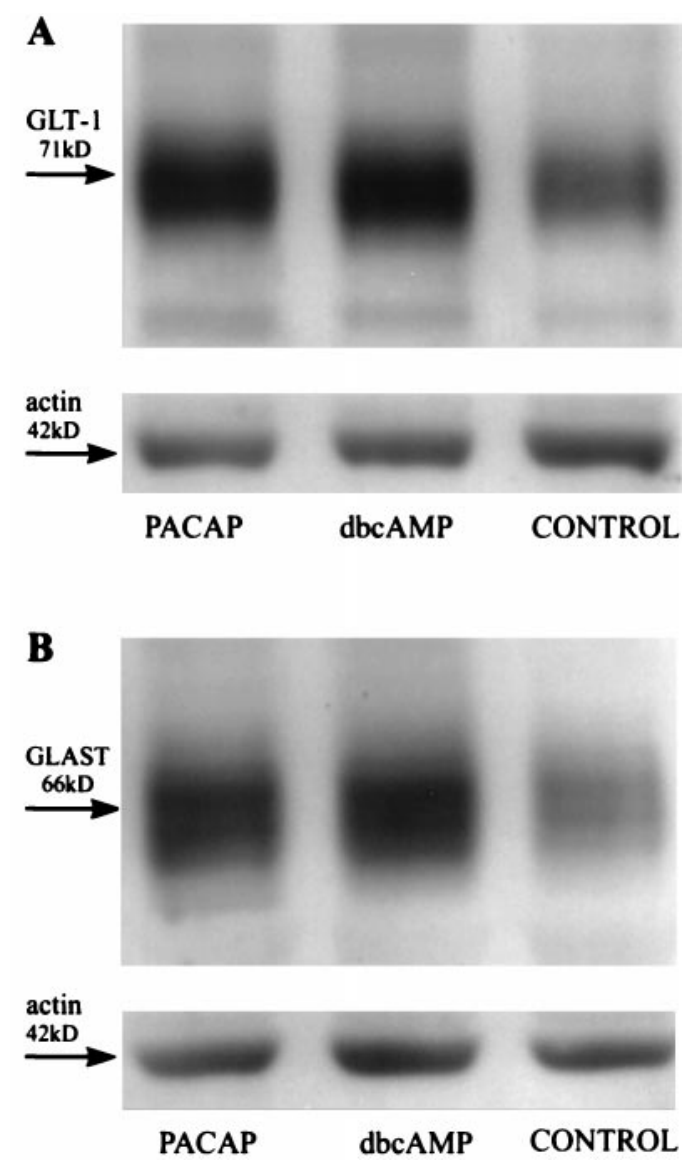

Figure 6. PACAP promotes the expression of glial glutamate transporters. Third passage cortical glia were maintained for $3 \mathrm{~d}$ in the absence or presence of PACAP $\left(10^{-7} \mathrm{M}\right)$ or dbcAMP $\left(10^{-4} \mathrm{M}\right)$ and immunoblotted with anti-GLT-1 antibodies $(1: 4000 ; A)$ or anti-GLAST antibodies (1: $1000 ; B)$. In each lane $5 \mu \mathrm{g}$ of total protein was loaded. Loading was controlled by staining the blots with actin antiserum.

glial glutamate uptake, PACAP also promotes glutamate metabolism in CNS glia.

\section{PACAP affects glial glutamate turnover via type-1 binding sites}

Two PACAP binding sites can be distinguished pharmacologically. Type-1 binding sites, corresponding to the PAC1 receptor (PAC1-R; see Discussion), show high-affinity binding for PACAP and bind VIP only with low affinity (for review, see Arimura, 1998). Type-2 binding sites (corresponding to VPAC1 and VPAC2 receptors) show high-affinity binding for both PACAP and VIP. To determine which of these binding sites (receptors) mediates the effects of PACAP on glial glutamate transporter expression, we initiated third passage glia from the cortical hemispheres of P1 rat pups and maintained them for $3 \mathrm{~d}$ with serial dilutions of PACAP-38 and VIP. Subsequent testing of the cultures for effects on glutamate transporter and GS expression by immunoblot analysis revealed that PACAP increases protein levels of GLT-1 at concentrations as low as $10^{-10} \mathrm{M}$ (Fig. 9A). A distinctly higher concentration of PACAP $\left(10^{-9} \mathrm{M}\right)$ was necessary to induce the expression of both GLAST and GS (Fig. 9B; data not shown). This is consistent with our previous notion that PACAP concentrations in neuron-CM are not sufficiently high to affect GLAST and GS expression. Maximal increases in GLT-1, GLAST, and GS levels were present with PACAP at $\geq 10^{-8} \mathrm{M}$.
VIP promoted the expression of both GLT-1 and GLAST only at concentrations of $\geq 10^{-8} \mathrm{M}$ (Fig. $\left.9 A, B\right)$. In addition, the effects of PACAP on glial glutamate transporter expression were sensitive to PACAP-(6-38) (data not shown), an antagonist for both PAC1 and VPAC1 receptors (Harmar et al., 1998). Together, these findings suggest that PACAP exerts its effects on glial glutamate turnover via type-1 binding sites (PAC1-R).

\section{PAC1 receptors use different signaling pathways to affect the expression of GLT-1 and GLAST}

The PAC1-R is positively coupled to both adenylate cyclase (AC) and phospholipase $\mathrm{C}$ (PLC). The events downstream of AC and PLC include the activation of PKA and PKC, respectively. PKA has been shown to mediate the effect of PACAP on neuronal survival, whereas PKC mediates the effects of PACAP on neurite outgrowth in PC12 cells (Kienlen-Campard et al., 1997; Villalba et al., 1997; Lazarovici et al., 1998; Vaudry et al., 1998). To determine the role of PKA and PKC in the effects of PACAP on glial glutamate transporter expression, we maintained third passage glia for $3 \mathrm{~d}$ with a combination of PACAP-38 and the PKA inhibitor H89 $\left(10^{-5} \mathrm{M}\right)$ or the PKC inhibitor Gö6976 $\left(10^{-6} \mathrm{M}\right)$. H89 almost completely abolished the PACAP-induced expression of GLAST and also decreased, although to a lesser extent, GLT-1 expression levels in PACAP-treated glia (Fig. 10). The presence of Gö6976 did not interfere with the effects of PACAP on GLAST expression but resulted in a robust inhibition of PACAPinduced GLT-1 expression (Fig. 10). Together, these findings reveal that PACAP differentially affects the expression of GLAST and GLT-1 via PKA and PKC.

\section{DISCUSSION}

In the brain, termination of glutamatergic neurotransmission is achieved predominantly by rapid uptake of synaptically released glutamate into astrocytes through the sodium-dependent glutamate transporters GLT-1 and GLAST and its subsequent conversion to glutamine by the enzyme GS (Rothstein et al., 1996; Sonnewald et al., 1997). To date, several factors, including glutamate itself, have been identified that rapidly alter the activity of the glutamate uptake process by post-translational modification of glutamate transporters (for review, see Gegelashvili and Schousboe, 1998). However, the factor or factors regulating the expression of glial glutamate transporter as well as of GS are still unknown. Pronounced increases in glial expression levels of GLT-1, GLAST, and GS have been observed in coculture systems with neurons (Hayashi et al., 1988; Swanson et al., 1997; Schlag et al., 1998). Although originally it had been suggested that these effects involve glutamate signaling, recent work by Schlag et al. (1998) demonstrated that neuronal influences on the expression of glial glutamate transporters are not abolished by various glutamate receptor antagonists. Interestingly, these studies further revealed that the effects of neurons on glial glutamate transporter expression are mimicked by the activation of cAMP-dependent signaling pathways (Swanson et al., 1997; Schlag et al., 1998).

Several of our present findings provide compelling evidence that neurons affect glial glutamate turnover via PACAP, the most potent activator of cAMP-dependent signaling pathways known to date. First, consistent with such a regulatory role, we observed that PACAP is synthesized exclusively by cortical neurons, but not by glia, as shown by RT-PCR analysis of neuronal and glial cultures for PACAP mRNA expression. It is of note that the lack of PACAP synthesis in cultured glia cannot be attributed to the absence of neurons in this culture system as judged from the 
$\mathbf{A}$

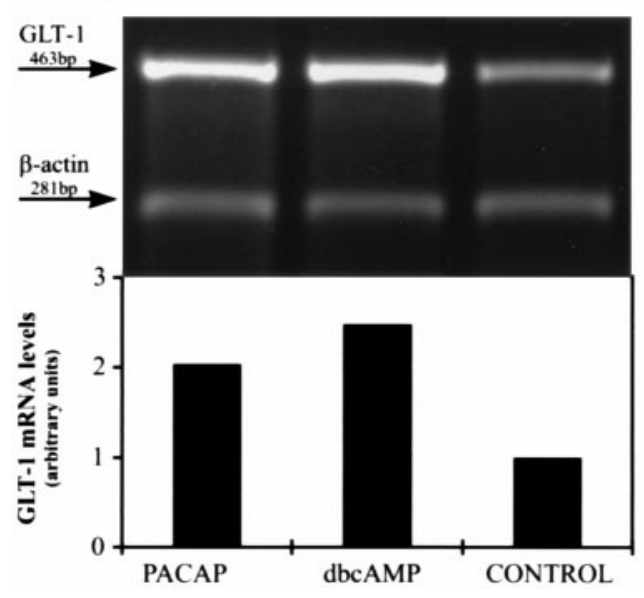

C

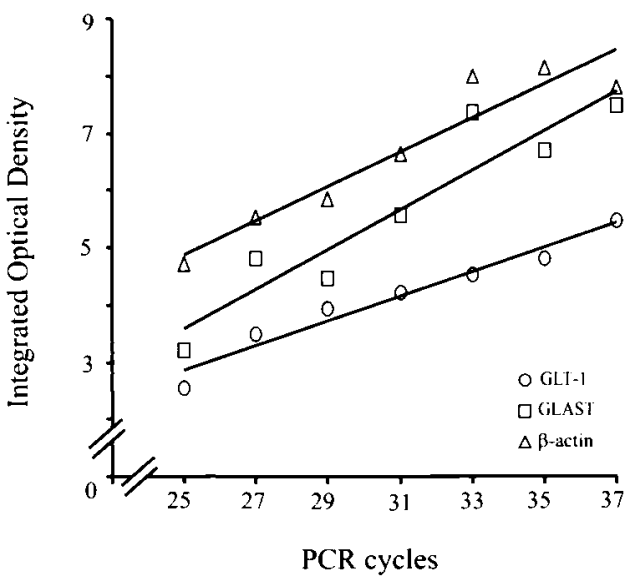

observation that treatment of glial cultures with either neuron-CM or neuronal membrane fractions failed to induce PACAP synthesis in glial cells. Although it cannot be dismissed completely that the differentiation process of glia in vitro might differ from that in vivo, we would like to emphasize that, in line with our present in vitro findings, all in vivo studies currently available point to neurons as the source for PACAP in the CNS (for example, see Koves et al., 1991; Kivipelto et al., 1992; Mikkelsen et al., 1994; Nielsen et al., 1998; Waschek et al., 1998). Second, further corroborating the role of PACAP as the physiological mediator of the effects of neurons on glial glutamate turnover, we found that the stimulatory effects of neuron-CM on glial GLT-1 expression were attenuated in the presence of inactivating PACAP antibodies or the PACAP receptor antagonist PACAP-(6-38). Moreover, the exposure of glia to PACAP robustly induced the expression of the glutamate-converting enzyme GS as well as of the glutamate transporters GLAST and GLT-1. The PACAP-induced increase in glutamate transporter levels correlated with an increase in the maximal velocity of the glutamate uptake. In addition, PACAP also increased the $K_{\mathrm{m}}$ of the uptake process. Similar increases in the $K_{\mathrm{m}}$ of glial glutamate uptake have been reported previously in studies with dbcAMP and have been attributed to an overestimation of the $K_{\mathrm{m}}$ value that may occur when enhanced glutamate transport would lower glutamate concentrations in the vicinity of the transporters (Schlag et al., 1998). Finally, using PACAP-induced $c$-fos expression as a readout for functional signal transduction (Engele and

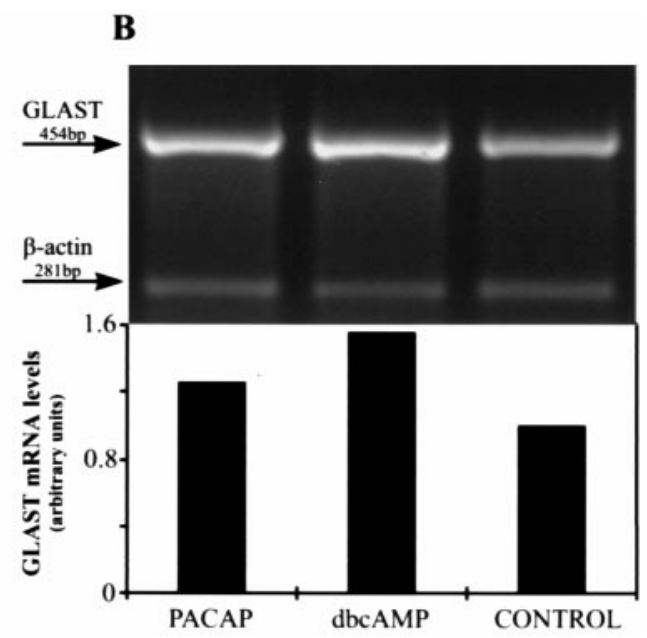

Figure 7. RT-PCR analysis of PACAP-treated cortical glia for GLT-1 $(A)$ and GLAST $(B)$ mRNA levels. Total mRNA was isolated from third passage cortical glia maintained for $3 \mathrm{~d}$ with either PACAP $\left(10^{-7} \mathrm{M}\right)$ or dbcAMP $\left(10^{-4} \mathrm{M}\right)$. Transporter and $\beta$-actin mRNAs were coamplified by 30 PCR cycles in the presence of different primer concentrations and separated on a $1.5 \%$ agarose gel. Graphs show the ratios of PACAP and $\beta$-actin RT-PCR products taken as a measure of transporter mRNA levels. $C$, Demonstration that, under the PCR conditions that were used, increasing numbers of PCR cycles led to a linear increase in the amount of the reaction products. PCR analysis was performed with total RNA isolated from untreated cortical glia in the presence of primers for GLT-1, GLAST, or $\beta$-actin.

Schilling, 1996) revealed that PACAP affects glial glutamate turnover via the direct and specific activation of glial PACAP receptors.

It is of note that PACAP affected the various components involved in glial glutamate turnover with different potencies. Whereas stimulatory effects of PACAP on GLT-1 expression were already detectable in the pico to nanomolar range, the regulation of GLAST and GS expression required $\sim 10$ times

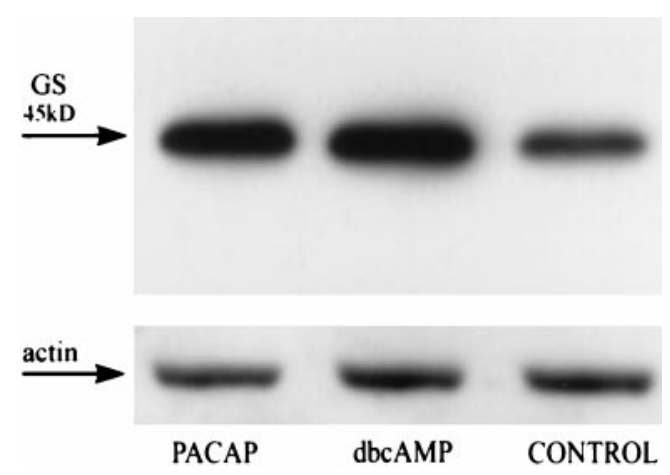

Figure 8. Immunoblot analysis of PACAP-treated cortical glia for GS expression levels. Third passage cortical glia were maintained for $3 \mathrm{~d}$ in the absence or presence of PACAP $\left(10^{-7} \mathrm{M}\right)$ or dbcAMP $\left(10^{-4} \mathrm{M}\right)$ and immunoblotted with anti-GS (1:1000). In each lane $5 \mu \mathrm{g}$ of protein was loaded. Loading was controlled by stripping off the GS staining and reprobing the blots with actin antiserum. 
A
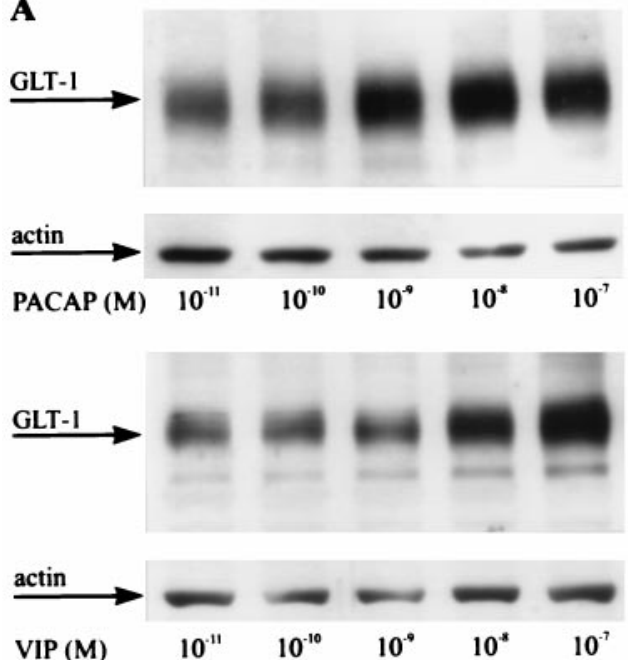

B
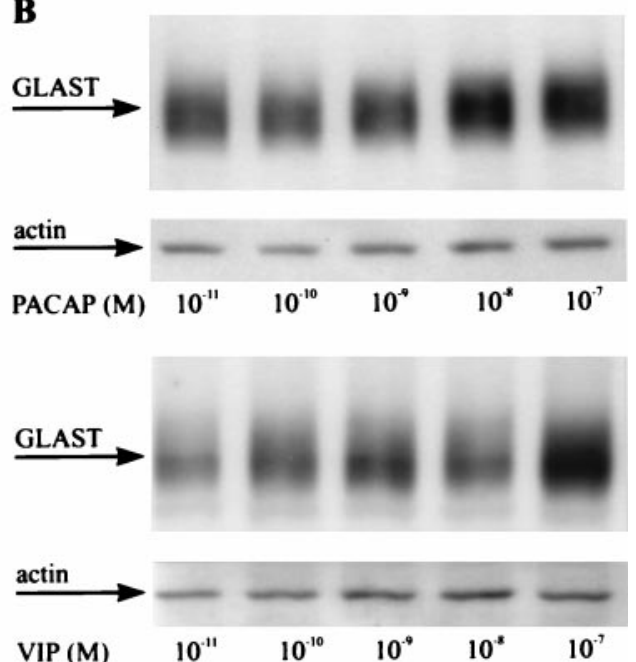

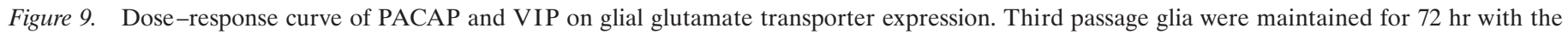

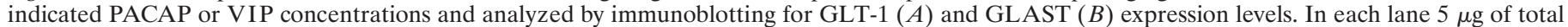

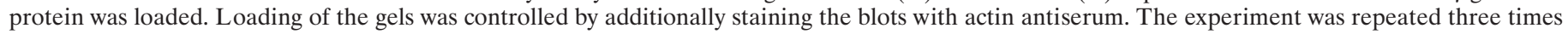

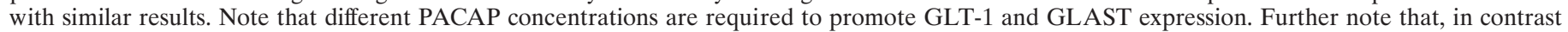
to PACAP, VIP is less potent in inducing glial glutamate transporter expression.
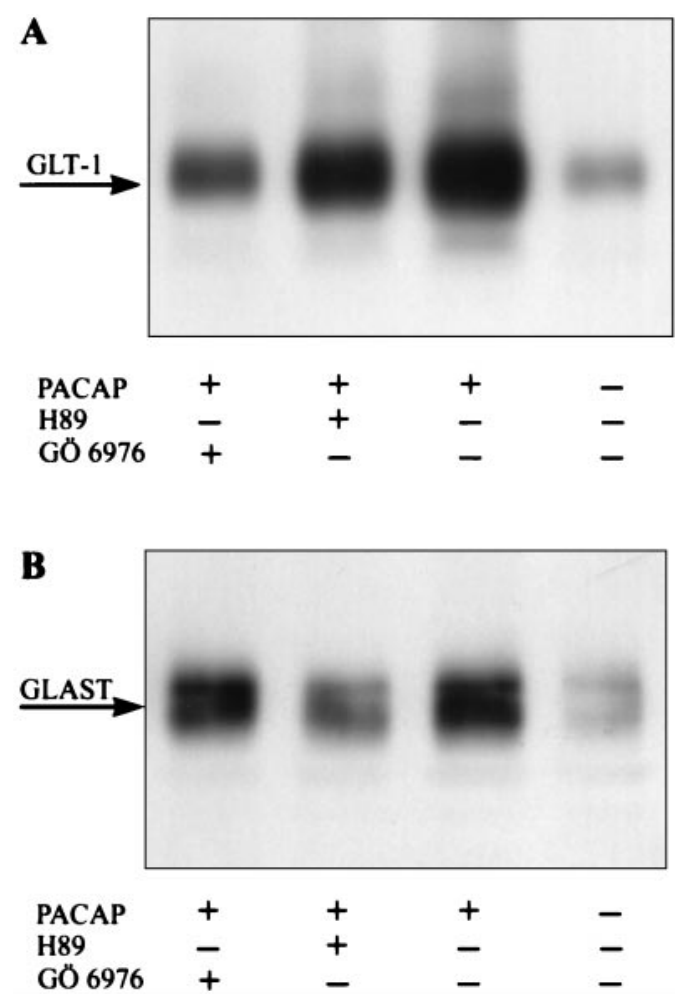

Figure 10. PACAP differentially uses PKA and PKC to affect the expression of glutamate transporters. Third passage glia were treated for 72 hr with PACAP $\left(10^{-7} \mathrm{M}\right)$ in combination with either H89 $\left(10^{-5} \mathrm{M}\right)$ or Gö6976 $\left(10^{-6} \mathrm{M}\right)$. Levels of GLT-1 $(A)$ and $\operatorname{GLAST}(B)$ were determined by immunoblot analysis. In each lane $5 \mu \mathrm{g}$ of total protein was loaded. The experiment was repeated three times with similar results.

higher PACAP concentrations. This points to the intriguing possibility that, depending on its extracellular concentration, PACAP allows for a stepwise or graded activation of glial glutamate turnover. Accordingly, moderate increases in extracellular
PACAP levels (up to $10^{-9} \mathrm{M}$ ) would promote the expression of GLT-1 preferentially, whereas increases beyond this concentration would, in addition, enhance the expression of GLAST and GS.

To date, three PACAP receptors, termed PAC1-R, VPAC1-R and VPAC2-R, have been cloned (for review, see Rawlings and Hezareh, 1996). All receptors bind PACAP with high affinity; however, they differ with respect to their affinity for VIP. PAC1-R is the PACAP-preferring receptor and shows an up to 1000-fold lower affinity for VIP. VPAC1-R and VPAC2-R bind PACAP38/27 and VIP with approximately equal nanomolar affinities. We revealed that PACAP, but not VIP, induced the expression of GLT-1 and GLAST in the pico to nanomolar range. In addition, we demonstrated that the effects of PACAP on glial glutamate transporter expression were attenuated in the presence of PACAP-(6-38), a nonspecific PACAP antagonist that binds to PAC1-R and VPAC1-R (Harmar et al., 1998). Together, these observations imply that the effects of PACAP on glial glutamate turnover are mediated via PAC1-R. PAC1-R are positively coupled to both AC and PLC. The only exception is the PAC1-R TM4 subtype that functions as an activator of L-type $\mathrm{Ca}^{2+}$ channels (Chatterjee et al., 1996). Previous studies suggested that PAC1-R TM4 is expressed by type-2, but not by type-1, astrocytes (Tatsuno and Arimura, 1994), the glial cell type predominantly present in our glial cultures (Franke et al., 1998).

Two crucial events downstream of AC and PLC are the activation of PKA and PKC, respectively. Both of these signaling proteins have been found to act as distinct mediators of the effects of PACAP on neuronal survival and neurite outgrowth (KienlenCampard et al., 1997; Villalba et al., 1997; Lazarovici et al., 1998; Vaudry et al., 1998). We observed that PACAP differentially signals via PKC and/or PKA to affect the glial glutamate uptake process. PACAP induced expression of GLAST via activation of PKA-dependent signaling pathways only, but it affected the expression of GLT-1 via both PKA and PKC-dependent signaling pathways. The diverse role of PKA and PKC in the effects of PACAP on glial glutamate transporter expression is of special interest given the fact that, in addition to PAC1-R TM4, a number 
of other PAC1-R mRNA splice variants exist. These include a short (PAC1-R s) as well as a very short (PAC1-R vs) form that lacks 21 amino acids in the N-terminal extracellular domain (Pantaloni et al., 1996). Other splice variants contain either one or two additional cassettes, termed "hip" and "hop1/2" (Spengler et al., 1993). When expressed in the renal cell line LLC PK1, these splice variants induce cAMP and inositol phosphates to different levels, probably because they interact with different G-proteins (Spengler et al., 1993). Direct functional consequences of the differential expression of the various PAC1-R isoforms have been demonstrated recently with primary neuronal precursors (Lu et al., 1998). Sympathetic neuroblasts, which express the "hop" receptor isoform, respond to PACAP by proliferation, whereas cerebral neuroblasts, expressing PAC1-R s, cease to divide in the presence of PACAP. By analogy, one could imagine a scenario in which, depending on the astrocytic PAC1-R make-up, PACAP would affect the expression of GLT-1 and GLAST differentially, thus allowing for a modulation or fine tuning of PACAP effects on astrocytic glutamate uptake. Whether in addition to regulating the expression of glial glutamate transporters PACAP also would affect the activity of glial glutamate uptake by post-translational modification of the transporters remains to be established. It is, however, of note that PACAP cooperates with glutamate to induce the release of arachidonic acid (Stella and Magistretti, 1996), a signaling molecule known to alter GLT-1 and GLASTmediated glutamate uptake rapidly (Zerangue et al., 1995).

A close correlation between hyper- or hypoactivity of glial glutamate turnover and distinct glutamate-associated diseases has been suggested repeatedly. Currently, the loss of GLT-1 and subsequent increases in extracellular glutamate are viewed as a major cause for the neurodegenerative processes underlying sporadic ALS (Bristol and Rothstein, 1996). In line with this assumption the inhibition of glutamate transporter expression in vivo was found to induce neurodegeneration and progressive paralysis (Rothstein et al., 1996). On the other hand, increased glutamate uptake eventually leads to glutamatergic hypofunction, a mechanism implied in schizophrenia and other psychoses (Carlson and Carlson, 1990) The present identification of PACAP as a neuronal-derived peptide with potent effects on the expression of glial glutamate transporters and GS points to a crucial role of this neuropeptide in the pathophysiology of glutamate-associated psychiatric and neurological diseases.

\section{REFERENCES}

Arimura A (1992) Pituitary adenylate cyclase-activating polypeptide (PACAP): discovery and current status of research. Regul Pept 37:287-303.

Arimura A (1998) Perspectives on pituitary adenylate cyclase-activating polypeptide (PACAP) in the neuroendocrine, endocrine, and nervous system. Jpn J Physiol 48:301-331.

Arizza JL, Fairman WA, Wadliche JI, Murdoch GH, Kavanaugh MP, Amara SG (1994) Functional comparison of three glutamate transporter subtypes cloned from human motor cortex. J Neurosci 14:5559-5569.

Bristol LA, Rothstein JD (1996) Glutamate transporter gene expression in amyotrophic lateral sclerosis motor cortex. Ann Neurol 39:676-686.

Carlson M, Carlson A (1990) Interactions between glutamatergic and monoaminergic systems within the basal ganglia-implications for schizophrenia and Parkinson's disease. Trends Neurosci 13:272-276.

Chatterjee TK, Sharma RV, Fisher RA (1996) Molecular cloning of a novel variant of the pituitary adenylate cyclase-activating polypeptide (PACAP) receptor that stimulates calcium influx by activation of L-type calcium channels. J Biol Chem 271:32226-32232.

Engele J (1998) Spatial and temporal growth factor influences on developing midbrain dopaminergic neurons. J Neurosci Res 53:405-414.

Engele J, Bohn C (1992) Effects of acidic and basic fibroblast growth factors (aFGF, bFGF) on glial precursor cell proliferation: age dependency and brain region specificity. Dev Biol 152:363-372.

Engele J, Schilling K (1996) Growth factor-induced $c$-fos expression defines distinct subsets of midbrain dopaminergic neurons. Neuroscience 73:397-406.

Fairman WA, Vandenberg RJ, Arriza JL, Kavanaugh MP, Amara SG (1995) An excitatory amino acid transporter with properties of a ligand-gated chloride channel. Nature 375:599-603.

Franke B, Figiel M, Engele J (1998) CNS glia are targets for GDNF and neurturin. Histochem Cell Biol 110:595-601.

Garlin AB, Sinor AD, Sinor JD, Jee SH, Grinspan JB, Robinson MB (1995) Pharmacology of sodium-dependent high-affinity $\mathrm{L}-\left[{ }^{3} \mathrm{H}\right]$ glutamate transport in glial cultures. J Neurochem 64:2572-2580.

Gegelashvili G, Schousboe A (1998) Cellular distribution and kinetic properties of high-affinity glutamate transporters. Brain Res Bull 45:233-238.

Hallermayer K, Hamprecht B (1984) Cellular and functional heterogeneity in primary cultures of brain cells revealed by immunocytochemical localization of glutamine synthetase. Brain Res 295:1-11.

Harmar AJ, Arimura A, Gozes I, Journot L, Laburthe M, Pisegna JR, Rawlings SR, Robberecht P, Said SI, Sreedharn SP, Wank SA, Waschek JA (1998) International Union of Pharmacology. XVIII. Nomenclature of receptors for vasoactive intestinal peptide and pituitary adenylate cyclase-activating polypeptide. Pharmacol Rev 50:265-270.

Hayashi M, Hayashi R, Tanii H, Hashimoto K, Patel AJ (1988) The influence of neuronal cells on the development of glutamine synthetase in astrocytes in vitro. Dev Brain Res 41:37-42.

Kanai Y, Hediger MA (1992) Primary structure and functional characterization of a high-affinity glutamate transporter. Nature 360:467-471.

Kienlen-Campard P, Crochemore C, Rene F, Monnier D, Koch B, Loeffler JP (1997) PACAP type 1 receptor activation promotes cerebellar neuronal survival through the cAMP/PKA signaling pathway. DNA Cell Biol 16:323-333.

Kivipelto L, Absood A, Arimura A, Sundler F, Hakason R, Panula P (1992) The distribution of pituitary adenylate cyclase-activating polypeptide-like immunoreactivity is distinct from helodermin- and helospectin-like immunoreactivities in the rat brain. J Chem Neuroanat 5:85-94.

Koves K, Arimura A, Gorcs TG, Somogyvari-Vigh A (1991) Comparative distribution of immunoreactive pituitary adenylate cyclaseactivating polypeptide and vasoactive intestinal polypeptide in rat forebrain. Neuroendocrinology 54:159-169.

Lazarovici P, Jiang H, Fink Jr D (1998) The 38-amino-acid form of pituitary adenylate cyclase-activating polypeptide induces neurite outgrowth in PC12 cells that is dependent on protein kinase $\mathrm{C}$ and extracellular signal-regulated kinase, but not on protein kinase $\mathrm{A}$, nerve growth factor receptor tyrosine kinase, p $21{ }^{\text {ras }}$ G-protein, and pp60 ${ }^{\text {c-src }}$ cytoplasmic tyrosine kinase. Mol Pharmacol 54:547-558.

Lehre KP, Levy LM, Ottersen OP, Storm-Mathisen J, Danbolt NC (1995) Differential expression of two glial glutamate transporters in the rat brain: quantitative and immunocytochemical observations. J Neurosci 15:1835-1853.

Lin C-LG, Tzingounis AV, Jin L, Furuta A, Kavanaugh M, Rothstein JD (1998) Molecular cloning and expression of the rat EAAT4 glutamate transporter subtype. Mol Brain Res 63:174-179.

Liu GJ, Madsen BW (1997) PACAP-38 modulates activity of NMDA receptors in cultured chick cortical neurons. J Neurophysiol 78:2231-2234.

Lu N, Zhou R, DiCocco-Bloom E (1998) Opposing mitogenic regulation of PACAP in sympathetic and cerebral cortical precursors correlates with differential expression of PACAP receptor (PAC1-R) isoforms. J Neurosci Res 53:651-662.

Magistretti PJ, Cardinaux J-R, Martin J-L (1998) VIP and PACAP in the CNS: regulators of glial energy metabolism and modulators of glutamatergic signaling. Ann NY Acad Sci 865:213-225.

Martin J-L, Gasser D, Magistretti PJ (1995) Vasoactive intestinal peptide and pituitary adenylate cyclase-activating polypeptide potentiate $c$-fos expression induced by glutamate in cultured cortical neurons. J Neurochem 65:1-9.

Mikkelsen JD, Hannibal J, Larsen PJ, Fahrenkrug J (1994) Pituitary adenylate cyclase-activating peptide (PACAP) mRNA in the rat neocortex. Neurosci Lett 171:121-124.

Moroo I, Tatsuno I, Uchida D, Tanaka T, Saito J, Saito Y, Hirai A (1998) Pituitary adenylate cyclase-activating polypeptide (PACAP) stimulates 
mitogen-activated protein kinase (MAPK) in cultured rat astrocytes. Brain Res 795:191-196.

Nielsen HS, Hannibal J, Fahrenkrug J (1998) Embryonic expression of pituitary adenylate cyclase-activating polypeptide in sensory and autonomic ganglia and in the spinal cord of the rat. J Comp Neurol 394:403-415.

Olney JW (1990) Excitotoxic amino acids and neuropsychiatric disorders. Annu Rev Pharmacol Toxicol 30:47-71.

Pantaloni C, Brabet P, Bilanges B, Dumuis A, Housami S, Spengler D, Bockaert J, Journot L (1996) Alternative splicing in the N-terminal extracellular domain of the pituitary adenylate cyclase-activating polypeptide (PACAP) receptor modulates receptor selectivity and relative potencies of PACAP-27 and PACAP-38 in phospholipase C activation. J Biol Chem 271:22146-22151.

Pellegri G, Magistretti PJ, Martin J-L (1998) VIP and PACAP potentiate the action of glutamate on BDNF expression in mouse cortical neurones. Eur J Neurosci 10:272-280.

Pesce AM, Cibati M, Dell'Anna L, Fiorilli M, Carbonari M (1996) Optimization of quantitative co-amplification of beta-globin and HIV-1 sequences. Trends Genet 12:447-448.

Pines G, Danbolt NC, Bjoras M, Zhang Y, Bendahan A, Eide L, Koepsell H, Strom-Mathisen J, Seeberg E, Kanner BI (1992) Cloning and expression of a rat L-glutamate transporter. Nature 360:464-467.

Rawlings S, Hezareh M (1996) Pituitary adenylate cyclase-activating polypeptide (PACAP) and PACAP/VIP receptors: actions on the anterior pituitary gland. Endocr Rev 17:4-29.

Rothstein JD, Martin L, Levey AI, Dykes-Hoberg M, Jin L, Wu D, Nash N, Kuncl RW (1994) Localization of neuronal and glial glutamate transporters. Neuron 13:713-725.

Rothstein JD, Dykes-Hoberg M, Pardo CA, Bristol LA, Jin L, Kuncl RW, Kanai Y, Hediger MA, Wang Y, Schielke JP, Welty DF (1996) Knockout of glutamate transporters reveals a major role for astroglial transport in excitotoxicity and clearance of glutamate. Neuron 16:675-686.

Schilling K, Luk D, Morgan JI, Curran T (1991) Regulation of fos-lacZ fusion gene: a paradigm for quantitative analysis of stimulus transcription coupling. Proc Natl Acad Sci USA 88:5665-5669.

Schlag BD, Vondrasek JR, Munir M, Kalandadze A, Zelenaia OA, Rothstein JD, Robinson MB (1998) Regulation of glial $\mathrm{Na}^{+}$dependent glutamate transporters by cyclic AMP analogs and neurons. Mol Pharmacol 53:355-369.

Smeyne RJ, Schilling K, Robertson L, Luk D, Oberdick J, Curran T, Morgan JI (1992) Fos-lacZ transgenic mice: mapping sites of gene induction in the central nervous system. Neuron 8:13-23.

Sonnewald U, Westergaard N, Schousboe A (1997) Glutamate transport and metabolism in astrocytes. Glia 21:56-63.

Spengler D, Waeber C, Pantaloni C, Holsboer F, Bockaert J, Seeburg PH, Journot L (1993) Differential signal transduction by five splice variants of the PACAP receptor. Nature 365:170-175.

Stella N, Magistretti PJ (1996) Vasoactive intestinal peptide (VIP) and pituitary adenylate cyclase-activating polypeptide (PACAP) potentiate the glutamate-evoked release of arachidonic acid from mouse cortical neurons. Evidence for a cAMP-independent mechanism. J Biol Chem 271:23705-23710.

Storck T, Schulte S, Hofmann S, Stoffel W (1992) Structure, expression, and functional analysis of a $\mathrm{Na}^{+}$-dependent glutamate/aspartate transporter from rat brain. Proc Natl Acad Sci USA 89:10955-10959.

Swanson RA, Liu J, Miller JW, Rothstein JD, Farrell K, Stein BA, Longuemare MC (1997) Neuronal regulation of glutamate transporter subtype expression in astrocytes. J Neurosci 17:932-940.

Takei N, Skoglösa Y, Lindholm D (1998) Neurotrophic and neuroprotective effects of pituitary adenylate cyclase-activating polypeptide (PACAP) on mesencephalic dopaminergic neurons. J Neurosci Res 54:698-706.

Tanaka K, Watase K, Manabe T, Yamada K, Watanabe M, Takahasshi K, Iwama H, Nishikawa T, Ichihara N, Kikuchi T, Okuyama S, Kawashima N, Hori S, Takimoto M, Wada K (1997) Epilepsy and exacerbation of brain injury in mice lacking the glutamate transporter GLT-1. Science 276:1699-1702.

Tatsuno I, Arimura A (1994) Pituitary adenylate cyclase-activating polypeptide (PACAP) mobilizes intracellular free calcium in cultured rat type-2, but not type-1, astrocytes. Brain Res 662:1-10.

Tatsuno I, Morio H, Tanaka T, Uchida D, Hirai A, Tamura Y, Saito Y (1996) Pituitary adenylate cyclase-activating polypeptide (PACAP) is a regulator of astrocytes: PACAP stimulates proliferation and production of interleukin-6 (IL-6), but not nerve growth factor (NGF), in cultured rat astrocytes. Ann NY Acad Sci 805:482-488.

Torp R, Hoover F, Danbolt NC, Storm-Mathisen J, Ottersen OP (1997) Differential distribution of the glutamate transporters GLT1 and rEAAC1 in rat cerebral cortex and thalamus: an in situ hybridization analysis. Anat Embryol (Berl) 1997:317-326.

Vaudry D, Gonzales BJ, Basille M, Anouar Y, Fournier A, Vaudry H (1998) Pituitary adenylate cyclase-activating polypeptide stimulates both $c$-fos gene expression and cell survival in rat cerebellar granule neurons via activation of the protein kinase A pathway. Neuroscience 84:801-812.

Villalba M, Bockaert J, Journot L (1997) Pituitary adenylate cyclaseactivating polypeptide (PACAP-38) protects cerebellar granule neurons from apoptosis by activating the mitogen-activated protein kinase (MAP kinase) pathway. J Neurosci 17:83-90.

Waschek JA, Casillas RA, Nguyen TB, DiCocco-Bloom EM, Carpenter EM, Rodriguez WI (1998) Neural tube expression of pituitary adenylate cyclase-activating peptide (PACAP) and receptor: potential role in patterning and neurogenesis. Proc Natl Acad Sci USA 95:9602-9607.

Whetsell Jr WO, Shapira NA (1993) Neuroexcitation, excitotoxicity, and human neurological disease. Lab Invest 68:372-387.

Zerangue N, Arizza GL, Amara SG, Kavanaugh MP (1995) Differential modulation of human glutamate transporter subtypes by arachidonic acid. J Biol Chem 270:6433-6435. 